\title{
Obstructive sleep apnea among commercial vehicle drivers in Malaysia: Issues and initiatives
}

\author{
Ameer Batcha Wahida1, Othman Ilhamah ${ }^{1}$, Ahmad Mohamad Suffian ${ }^{1}$, Mohd Fahmi Aimi ${ }^{1}$, \\ Mohamed Norlen ${ }^{1^{*}}$, Shaw Voon Wong ${ }^{2}$ \\ ${ }^{1}$ Vehicle Safety and Biomechanics Research Centre, Malaysian Institute of Road Safety Research, Selangor, Malaysia; \\ *Corresponding Author: norlen@miros.gov.my \\ ${ }^{2}$ Director General Office, Malaysian Institute of Road Safety Research, Selangor, Malaysia \\ Received 18 June 2013; revised 18 July 2013; accepted 3 August 2013
}

Copyright (C) 2013 Ameer Batcha Wahida et al. This is an open access article distributed under the Creative Commons Attribution License, which permits unrestricted use, distribution, and reproduction in any medium, provided the original work is properly cited.

\begin{abstract}
Obstructive Sleep Apnea (OSA) has been identified by many studies as one of the significant contributing factors for motor vehicle accidents. However, only a small number of studies have been conducted in Malaysia. Objective: This paper aims to highlight the prevalence of OSA among truck drivers and express bus drivers in Malaysia and efforts being undertaken to address issues related to OSA among commercial vehicle drivers. Methodology: Two separate studies were conducted: a cross sectional study among truck drivers and secondly among express bus drivers. The screening process for identifying the high risk group for OSA was done using Berlin questionnaire. Meanwhile, among express bus drivers, OSA was confirmed with sleep study using polysomnography test. Result: Screening of risk group of OSA among truck drivers revealed that $14.6 \%$ (19) of drivers were categorized as having high risk of OSA while $85.4 \%$ (111) having low risk of OSA. While, in another study, polysomnography test among express bus drivers showed that $83(28.7 \%)$ had mild OSA, $26(9.0 \%)$ had AHI moderate OSA, and 19 drivers (6.6\%) severe OSA. Conclusion: This paper highlighted the issues of OSA among commercial vehicle drivers in Malaysia. With an alarming high prevalence, OSA should be a major road safety concern in this country. A special study focusing on sleep and fatigue related crashes may need to be conducted to complement the current studies and full implementation of existing efforts and initiatives to address OSA in road crashes should be realized by the relevant authorities.
\end{abstract}

Keywords: OSA; Obstructive Sleep Apnea; Commercial Vehicle Drivers

\section{INTRODUCTION}

Obstructive Sleep Apnea (OSA) has been identified by many studies as one of the significant contributing factors for motor vehicle crashes. Persons with OSA are likely to fall asleep during driving due to poor sleep quality. OSA has been defined as a common disorder and a person with OSA may experience one or more pauses in breathing or in shallow breathing while sleeping and repetitive episodes of apnea or hypopnea due to obstruction of the upper respiratory airway. The breathing process will stop for ten seconds or more due to the occurrence of the obstruction of the upper airway due to the relaxation of dilating muscles which fail to keep the upper airway opened [1]. With this cessation of breathing, the oxygen level in blood may reduce and the person might arouse from sleep a few times and end up with poor sleep quality. The disruption of nighttime sleep may result in excessive daytime sleepiness. In addition, people with sleep apnea may feel tired and lose focus during the day due to poor sleep quality. This might be dangerous for a person who works as a driver during the day such as truck drivers.

In most countries in the world including Malaysia, people who drive commercial vehicles such as taxis, buses, or trucks normally do shift work which needed them not to follow the regular and normal sleep pattern. Their nature of work and sleeping pattern may lead to fatigue and sleepiness. In addition, drivers with OSA with combination of the nature of their work such as long distance driving and driving during the wee-hours had put them in increasing risk to experience fatigue and sleepiness at the wheel. According to Norlen et al., 2008, fatigue status among bus drivers has been shown to in- 
crease with the duration of driving and working [2].

The prevalence of OSA among commercial vehicle drivers is relatively common as compared to general population. Prevalences of OSA among adult general population as reported in various epidemiological studies vary from $0.3 \%$ to $10 \%$ in majority of the studies which reported prevalence below $6 \%$ [3]. In contrast, a study conducted by Moreno in 2004 shows about $26 \%$ of truck drivers having high risk of OSA after being screened using the Berlin questionnaire [4]. In a similar study, about $28 \%$ of commercial truck drivers were found to have OSA symptoms [5]. According to a study conducted by Pack et al. in 2002 among commercial drivers in Pennsylvania, the researchers reported that about $17.6 \%$ of drivers had mild OSA, $5.8 \%$ had moderate OSA and 4.7\% had severe OSA [6]. Furthermore, in a recent survey conducted by Federal Motor Carrier Safety Administration, they found that OSA affects more than $40 \%$ of commercial drivers in United States. Moreover, it is interesting to highlight that one of every three 18 -wheelers in United States had found to have a driver suffer the OSA [7].

The relationship between sleep apnea and motor vehicle crash (MVC) has been recognized for over a decade. Many studies have shown the relationship between MVC and OSA. Based on a systematic review conducted by Ellen et al. 2006, seven out of 18 studies have found statistically significant positive relationship between severity of OSA and risk of crash. In addition to that, the strength of the association was found to be approximately two folds in the studies with the positive relationship [8]. Those findings have been supported by another similar systematic review done by Tregear et al. in 2009, they found that individuals with OSA were clearly having increased risk for crash with the mean crash-rate ratio associated with OSA was likely to fall within the range of 1.21 to 4.89 [9].

Similarly, another study conducted by Findley et al. (1988) reported that patients with sleep apnea had a seven-fold greater risk of road accidents compared to normal patients [10]. In addition, about $24 \%$ of OSA patients were reported to have fallen asleep at least once per week while driving. Later studies show that there may be as much as a 15 -fold increase in risk for OSA drivers compared with those without the condition [11, 12].

Thus, from studies carried out in all parts of the world, the prevalence of OSA among commercial drivers has been found to be quite high and also has an established association with crash. However, only a small number of studies have been conducted in this country. Therefore, this paper aims to highlight the issues related to OSA among commercial vehicle drivers in Malaysia taking into an example of the two studies conducted among truck and express bus drivers. The paper is also intended to highlight efforts and initiatives to address the issues related to OSA among commercial vehicle drivers.

\section{METHODOLOGY}

\subsection{Subject Selection}

All truck drivers from a logistic company were recruited for the study. A total of 130 commercial truck participated in the study. Meanwhile, for study among express bus drivers, 292 bus drivers were randomly selected from a list of drivers obtained from five express bus companies operated in Malaysia. All drivers were commercial vehicle license holders and able to communicate either in Malay or English. Drivers with mental or psychiatric illness were excluded.

\subsection{Data Collection Method}

\subsubsection{Screening of OSA}

Malay version of Berlin questionnaire was used to assess high risk group of OSA among drivers. Physical assessment was carried out to obtain BMI, blood pressure and neck circumference of drivers. A written informed consent was obtained from participants prior to the data collection process. Each participant was required to complete the Berlin questionnaire and a socio-demographic form before proceeding with the physical measurement. Tokens were rewarded to the participant at the end of the session.

\subsubsection{Confirmatory Sleep Test}

For express bus drivers, all of them were subjected to polysomnography testing at a local university hospital to confirm the status of OSA after they had completed the Berlin Questionnaire. However, for truck drivers, no confirmation with polysomnography test was done due to budget constraint.

\subsection{Statistical Analysis}

Specifically for the cross sectional study among truck drivers, data was analyzed using statistical software SPSS version 20. Frequency distribution and proportion was used to describe categorical variables while mean and SD for quantitative variables. Odds ratio was calculated to determine the association of OSA risk group and MVC.

\section{RESULTS}

\subsection{Prevalence of OSA among Commercial Vehicle Driver}

Screening of risk group of OSA among truck drivers revealed that $14.6 \%$ (19) of drivers were categorized as having high risk of OSA while $85.4 \%$ (111) having low risk of OSA. In contrast, based on polysomnography test 
using an Embletta ${ }^{\circledR}$ X100 device findings showed that 128 of express bus drivers (44.3\%) had AHI of 5 or more episodes per hour of sleep, 83 (28.7\%) had AHI of 5 to $<15$ or mild OSA, $26(9.0 \%)$ had AHI of 15 to $<30$ or moderate OSA, and 19 drivers $(6.6 \%)$ had 30 or more episodes of AHI per hour of sleep, which represents severe OSA.

\subsection{Associated Factors of OSA}

Table 1 represent a summary of occurrence of related symptoms and characteristics between high risk and low risk group of truck drivers as well as OSA and non OSA case of bus drivers. Study among both groups of drivers (bus drivers and truck drivers) revealed that snoring were significantly higher among drivers with OSA and high risk group. However, frequent waking while sleeping were significantly higher among bus drivers with OSA while witnessed apnea among truck drivers were significantly higher among high risk group of OSA. Both groups of drivers reported no significant difference in the occurrence of morning headache, and daytime somnolence or excessive daytime sleepiness.

Table 1. Differences in the occurrence of related symptoms and characteristics between high and low risk of OSA.

\begin{tabular}{|c|c|c|c|c|c|c|c|c|c|c|}
\hline \multirow[b]{2}{*}{ Variables } & \multicolumn{5}{|c|}{ Commercial Bus Driver } & \multicolumn{5}{|c|}{ Commercial Truck Driver } \\
\hline & \multicolumn{2}{|c|}{ OSA } & \multicolumn{2}{|c|}{ Non-OSA } & p-value & \multicolumn{2}{|c|}{ High risk of OSA } & \multicolumn{2}{|c|}{ Low risk of OSA } & p-value \\
\hline Age (year) & - & $45.4(7.0)$ & - & $42.5(7.6)$ & $0.001^{\mathrm{a}}$ & - & $40.2(8.8)$ & - & $38.7(10.9)$ & $0.579^{\mathrm{a}}$ \\
\hline BMI $\left(\mathrm{kg} / \mathrm{m}^{2}\right)$ & - & $29.4(4.9)$ & - & $25.7(4.1)$ & $<0.001^{\mathrm{a}}$ & - & $30.6(3.8)$ & - & $24.8(4.6)$ & $<0.001^{\mathrm{a}}$ \\
\hline Neck circumference $(\mathrm{cm})$ & - & $40.0(3.1)$ & - & $37.4(2.9)$ & $<0.001^{\mathrm{a}}$ & - & $40.9(2.4)$ & - & $38.2(3.0)$ & $<0.001^{\mathrm{a}}$ \\
\hline \multicolumn{11}{|l|}{ Smokers } \\
\hline Yes & $67(52.3)$ & - & $108(67.1)$ & - & $0.038^{\mathrm{b}}$ & $9(47.4)$ & - & $77(69.4)$ & - & $0.061^{\mathrm{b}}$ \\
\hline No & $61(47.7)$ & - & $53(32.9)$ & - & & $10(52.6)$ & - & $34(30.6)$ & - & \\
\hline \multicolumn{11}{|l|}{ Diabetes } \\
\hline No & $118(92.2)$ & - & $152(94.4)$ & - & & $17(89.5)$ & - & $106(95.5)$ & - & \\
\hline \multicolumn{11}{|l|}{ Hypertension/high blood pressure } \\
\hline Yes & $57(44.5)$ & - & $30(18.6)$ & - & $<0.001^{\mathrm{b}}$ & $2(10.5)$ & - & $32(28.8)$ & - & $0.093^{\mathrm{c}}$ \\
\hline No & $71(55.5)$ & - & $131(81.4)$ & - & & $17(89.5)$ & - & $79(71.2)$ & - & \\
\hline \multicolumn{11}{|l|}{ Witnessed apnoea } \\
\hline Yes & $7(5.5)$ & - & $4(2.5)$ & - & $0.225^{\mathrm{c}}$ & $3(15.8)$ & - & $3(2.7)$ & - & $0.012^{\mathrm{c}}$ \\
\hline No & $121(94.5)$ & - & $157(97.5)$ & - & & $16(84.2)$ & - & $108(97.3)$ & - & \\
\hline \multicolumn{11}{|l|}{ Morning headache } \\
\hline Yes & $12(9.4)$ & - & $10(6.2)$ & - & $0.314^{\mathrm{b}}$ & $1(5.3)$ & - & $5(4.5)$ & - & $0.884^{\mathrm{c}}$ \\
\hline \multicolumn{11}{|l|}{ Daytime somnolence } \\
\hline Yes & $8(6.3)$ & - & $8(5.0)$ & - & $0.636^{\mathrm{b}}$ & $4(78.9)$ & - & $15(13.5)$ & - & $0.390^{\mathrm{c}}$ \\
\hline No & $120(93.7)$ & - & $153(95.0)$ & - & & $15(21.1)$ & - & $96(86.5)$ & - & \\
\hline \multicolumn{11}{|l|}{ Snoring } \\
\hline Yes & $105(82.0)$ & - & $87(54.0)$ & - & $<0.001^{\mathrm{b}}$ & $18(94.7)$ & - & $27(31.4)$ & - & $<0.001^{\mathrm{b}}$ \\
\hline No & $23(18.0)$ & - & $74(46.0)$ & - & & $1(5.3)$ & - & $59(68.6)$ & - & \\
\hline \multicolumn{11}{|l|}{ Frequent waking while sleeping } \\
\hline Yes & $15(11.7)$ & - & $8(5.0)$ & - & $0.035^{\mathrm{b}}$ & $0(0)$ & - & $8(7.2)$ & - & $0.227^{\mathrm{c}}$ \\
\hline No & $113(88.3)$ & - & $153(95.0)$ & - & & $19(100.0)$ & - & $103(92.8)$ & - & \\
\hline
\end{tabular}

${ }^{a} p$ Value of $t$ statistics, ${ }^{b} p$ Value of chi-square test, ${ }^{c} \mathrm{p}$ Value of Fisher's exact test. 
The BMI (Mean $=30.6 \pm$ SD 3.8, $\mathrm{p}<0.001)$ and neck circumference (Mean $=40.9 \pm$ SD 2.4, $p<0.001)$ of the truck drivers were significantly higher among high risk group of OSA. Whereas among bus drivers, age (Mean = $45.4 \pm$ SD 7.0, $\mathrm{p}=0.001)$, BMI $($ Mean $=29.4 \pm$ SD 4.9, $\mathrm{p}<0.001$ ), neck circumference (Mean $=40.0 \pm$ SD 3.1, $\mathrm{p}$ $<0.001)$ and hypertension were significantly higher among those with OSA.

\subsection{Association of OSA and Motor Vehicle Crash (MVC)}

The odds ratio for history of MVC for the past three years was calculated between those with high and low risk of OSA as presented in Table 2. The result shows that there was a difference in the MVC involvement between the high risk group and low risk group. High risk group of OSA were more likely to be involved in MVC than low risk group. However, the difference was not statistically significant. This could be due to small sample size.

\subsection{Efforts \& Initiatives Relating to Fatigue Management and OSA}

In Malaysia, under the Road Transport Act (1987), all commercial vehicle drivers are required to obtain a medical certificate for application and renewal of his license on a yearly basis [13]. The medical certificate is to certify that he is not suffering from any disease or physical disability which is likely to interfere with the efficient discharge of his duties as a driver or to cause his driving of a commercial vehicle to be a source of danger to the public. Under the current regulation, Public Service Vehicles (Licensing and Conduct of Drivers, Conductors and Passengers) Rules 1959, the general rule indicates that a driving license should not be given or renewed to any candidates suffering from a medical condition likely to compromise safety on the road, except if certified medically fit by a medical practitioner. However, there was no specific medical conditions or disorders mentioned in the Road Transport Act (1987). "Medically

Table 2. Likelihood of OSA risk group involved in MVC among truck drivers.

\begin{tabular}{ccc}
\hline OSA screening & $\mathbf{N}(\%)$ & OR $(\mathbf{9 5 \%} \mathbf{C I})$ \\
\hline High risk & & \\
Involved in MVC & 8 & $1.58(0.52,4.72)$ \\
Not involved in MVC & 11 & \\
Low risk & & \\
Involved in MVC & 35 & \\
Not involved in MVC & 76 \\
\hline
\end{tabular}

fit to drive" is solely based on the professional judgement of medical practitioners who examine the case. Based on the previous approach, Sleep apnea was never been considered as one of the medical condition that need to be screened for many reasons which include weakness in the previous medical examination format, lack of aware- ness among general practitioners on sleep apnea, and lack of health facilities equipped with sleep study test. In addition, issues on sleep apnea and crash was never been highlighted prior to these two studies (Study among bus and truck drivers).

In view of the weakness of the current system, Road Transport Department of Malaysia in collaboration with the Ministry of Health and Malaysian Institute of Road Safety Research (MIROS) have established a medical standard as a guide for the purpose of medical examination as a pre-condition for licensing. Subsequently, in 2011, the Medical Examination Standard for Vocational Driver's Licensing was published by Ministry of Health. According to the standard, any applicant not fulfilling the criteria stated will be considered as unfit for a vocational driving license. In view of the high prevalence of sleep apnea among commercial vehicle drivers as reported by MIROS's studies, Obstructive Sleep Apnea was included in the standard [14].

Another initiative taken in Malaysia to tackle issues concerning commercial drivers is the Occupational Safety and Health of the Industry Code of Practice (ICOP) for Road Transport Activities 2010. The ICOP is applicable to vehicles involved in road transport activities including vehicles such as commercial vehicles, public service vehicles, goods vehicles and tourism vehicles [15]. One of the objectives of the ICOP is to manage issues related to drivers namely fatigue, sleepiness, and indirectly OSA.

\section{DISCUSSION}

This study revealed that $14.6 \%$ of commercial truck drivers were categorized as high risk group for OSA based on internationally validated tool: Berlin Questionnaire. Even though the result was not confirmed with polysomnography sleep study, it is highly likely that the prevalence is the true prevalence as the Berlin Questionnaire is a validated tool widely used for OSA screening with high sensitivity and specificity [16,17]. Based on the study conducted by Netzer and his colleague, the Berlin questionnaire has been evaluated in the population of Cleveland, Ohio with a sensitivity of 86 per cent and specificity of 77 per cent [16]. Similarly, a validation study conducted in India by Sharma et al. (2006) produced a comparable finding with $86 \%$ sensitivity and $95 \%$ specificity, positive and negative predictive values of 96 and $82 \%$. In their conclusion, Sharma et al. con- 
cluded that administration of Berlin Questionnaire can identify high risk subjects and can thus avoid unnecessary polysomnography studies especially in resourcelimited setting [17].

Among the truck drivers studied, snoring, witnessed apnea, BMI and neck circumference were found to be significantly higher among the high risk group of OSA. This is similar to the findings among the express bus drivers confirmed to have OSA. The same findings have also been presented by other studies utilizing confirmatory measures of OSA through sleep tests conducted elsewhere $[18,19]$. Due to financial limitations, the truck drivers who have been already been screened did not undergo further confirmatory test or sleep test. Results of the polysomnography tests for the express bus drivers show that the prevalence of sleep apnea as measured by the AHI was high with 44.3, 15.6, and 6.6 percent of the drivers suffering from mild, moderate, and severe OSA respectively. This finding is higher compared to studies in other places $[19,20]$.

In Malaysia, motor vehicle crashes involving commercial vehicles are alarming. Road accident statistics for a period of ten years from 2002 to 2011 have shown an increasing total number of busses and lorries involved in road crashes [21]. Meanwhile, annual statistics of MIROS crash investigations from the year 2007 to 2011 revealed that fatigue is among the highest contributor for crashes involving one to three fatalities (13.5\%) and crashes involving more than three fatalities $(20.8 \%)$. Fatigue has also been identified as the highest contributor for crashes at 53\% among bus and lorry drivers [22]. Fatigue among bus express was reported to be from $32 \%$ to $37.7 \%$ after the drivers completed their trips $[23,24]$. Fatigue is a common complaint in OSA and about $42 \%$ of those with OSA reported a significant amount of fatigue [25]. As the nature of work of bus and truck drivers involve driving long distances and rotating work shifts, it is more likely for this group of drivers with OSA to experience fatigue and sleepiness while driving.

The number of PSV and GDL license holders is showing a steady and increasing trend in the last ten years [26]. The increased exposure of bus and lorry drivers combined with the high prevalence of OSA among this group of drivers and their nature of work increases their risk of MVC involvement. OSA has been reported as a risk factor due to sudden performance impairment in driving and could lead to accidents [27]. The association between OSA and MVC has been well documented. Those with OSA had risk 2 to 7 times higher to be involved in MVC compared to those without OSA depending on its severity $[8,11,28]$. However, in this study we were unable to demonstrate the significant association between both. A possible explanation for this result is that the history of MVC obtained through question- naire was subjected to reporting bias. In addition, the study design used was not the best method in determineing the association of OSA and MVC. The more appropriate study design would be a case control or a cohort study. However, due to time and budget constraints, a cohort study would not be possible as it requires a longer follow up time and a big group of driver cohort. In contrast, difficulty in identifying the case of drivers limits the possibility of conducting a case control study. Moreover, current status of OSA based on Berlin Questionnaire or polysomnography test may not reflect the situation in the past.

Based on the results of the study, the importance of screening for the features and the risk of OSA among commercial vehicle drivers in Malaysia as part of a medical assessment for either initial licensing or renewal of a commercial vehicle driving license have been emphasized. Those with a high index of suspicion for OSA should be subjected to a sleep test to confirm the diagnosis, and finally treatment can be given accordingly. Due to this concern, Malaysia has taken an initiative of refining the current medical requirement for the pre-licensing of commercial vehicle drivers. OSA has been included as one of the criteria for medical examination of commercial vehicle driving license holders before being granted with new or renewed licenses. However, the implementtation of the medical examination according to the newly established medical examination standard for commercial vehicle drivers has yet to be on the ground as the efforts to materialize it are still in progress. Specific regulatory standards of OSA as one of the criteria for medical examination is well established and implemented in other countries such as United Kingdom, Sweden, Poland, Spain, Belgium, France, Denmark, Luxembourg, Portugal, Finland, Germany, Australia, Canada, New Zealand and United States [29].

In the ICOP published in 2010, as stated in Part 3 "Driver Management", there are four sub-elements which specifically cater to maintain driver fitness. The four sub-elements are driving hours and working hour limits, driver rotation system, driver monitoring, and driver health and welfare.

\section{Summary}

In summary, the prevalence of OSA among truck and express bus drivers as reported by our study is alarming. The results highlighted the importance of screening for the symptoms and the risk of OSA among commercial vehicle drivers in Malaysia as part of a medical assessment for either initial licensing or renewal of a commercial vehicle driving license. Finally, subsequent treatment of drivers with OSA may improve road traffic safety. A special study focusing on sleep and fatigue related crashes may need to be conducted to complement the 
current studies. Moreover, inter agencies collaboration and full implementation of existing efforts as well as initiatives to address OSA and driver fatigue in road crashes should be realized by the relevant authorities.

\section{ACKNOWLEDGEMENTS}

The study was commissioned by the Malaysian Institute of Road Safety Research (MIROS). Special thanks dedicated to MIROS Director General and all individuals who contributed either directly and indirectly to the study.

\section{REFERENCES}

[1] Downey, R., Gold P.M. and Wickramasinghe, H (2009) Obstructive sleep apnoea. http://emedicine.medscape.com/article/295807-overview

[2] Norlen, M., Fadhli, Y., Ilhamah, O., Rohayu, S. and Wong, S.V. (2008) Fatigue among commercial bus drivers in Malaysia: Role of driving hours and single versus twodriver approach. Malaysian Institute of Road Safety Research, Kuala Lumpur. doi:10.1183/09031936.02.00404502

[3] McNicholas, W.T. and Krieger, J. (2002) Public health and medicolegal implications of sleep apnoea. European Respiratory Journal, 20, 1594-1609.

[4] Moreno, C.R.C., Carvalho, F.A., Lorenzi, C., Matuzaki, L.S., Prezotti, S., Bighetti, P., Louzada, F.M. and LorenziFilho, G. (2004) High risk for obstructive sleep apnea in truck drivers estimated by the berlin questionnaire: Prevalence and associated factors. Chronobiology International, 21, 871-879. doi:10.1081/CBI-200036880

[5] Sassani, A., Findley, L.J., Kryger, M., Goldlust, E., George, C. and Davidson, T.M. (2004) Reducing motor-vehicle collisions, costs, and fatalities by treating obstructive sleep apnea syndrome, sleep disordered breathing. Sleep, 27, 453-458.

[6] Pack, A.I., Dinges, D.F. and Maislin, G. (2002) A study of prevalence of sleep apnea among commercial truck drivers. FMCSA, Washington DC.

[7] NRCME Training Online (2013) Obstructive Sleep Apnea (OSA): Its effects on commercial truck drivers. NRCME Training Online 2013.

[8] Ellen, R.L.B., Marshall, S.C., Palayew, M., et al. (2006) Systematic review of motor vehicle crash risk in persons with sleep apnea. Journal of Clinical Sleep Medicine, 2, 193-200.

[9] Tregear, S., Reston, J., Schoelles, K. and Phillips, B. (2009) Obstructive sleep apnea and risk of motor vehicle crash: Systematic review and meta-analysis. Journal of Clinical Sleep Medicine, 5, 573-581.

[10] Findley, L.J., Unverzagt, M.E. and Suratt, P.M. (1988) Automobile accidents involving patients with obstructive sleep apnea. American Review of Respiratory Disease, 138, 337-340. doi:10.1164/ajrccm/138.2.337

[11] Terán-Santos, A. Jiménez -Gómez, J., Ordero-Guevara, C. and the Cooperative Group Burgos-Santander (1999) The association between sleep apnea and the risk of traffic accidents. The New England Journal of Medicine, 340, 847-851. doi:10.1056/NEJM199903183401104

[12] Horstmann, S., Hess, C.W., Bassetti, C., Gugger, M. and Mathis, J. (2000) Sleepiness-related accidents in sleep apnea patients. Sleep, 23, 383-389.

[13] RTA (1987) Road traffic act. Malaysia Law, Act 333.

[14] Ministry of Health (2011) Medical examination standards for vocational driver's licensing.

[15] Occupational Safety and Health of the Industry Code of Practice for Road Transport Activities 2010, Department of Occupational Safety and Health, Ministry of Human Resources Malaysia, JKKP DP(S) 127/379/3-5, pp. 3-4.

[16] Netzer, N.C., Stoohs, R.A. and Netzer, C.M. (1999) Using the Berlin questionnaire to identify patients at risk for the sleep apnea syndrome. Annals of Internal Medicine, 131, 488. doi:10.7326/0003-4819-131-7-199910050-00002

[17] Sharma, S.K., Vasudev, C., Sinha, S., Banga, A., Pandey, R.M. and Handa, K.K. (2006) Validation of the modified Berlin questionnaire to identify patients at risk for the obstructive sleep apnoe syndrome. Indian Journal of Medical Research, 124, 281-290.

[18] Parks, P.D., Durand, G., Tsismenakis, A.J., Vela-Bueno, A. and Kales, S.N. (2009) Screening for obstructive sleep apnea during commercial driver medical examinations. JOEM, 51, 275-282.

[19] Hui, D.S.C., Chan, J.K.W., Ko, F.W.S, Choy, D.K.L., Li, T.S.T., Chan, A.T., Wong, K.K. and Lai, C.K.W. (2002) Prevalence of snoring and sleep-disordered breathing in a group of commercial bus drivers in Hong Kong. Internal Medicine Journal, 32, 149-157. doi:10.1046/j.1444-0903.2001.00196.x

[20] Gurubhagavatula, I., Maislin, G., Nkwuo, J.E. and Pack, A.I. (2004) Occupational screening for obstructive sleep apnoea in commercial drivers. American Journal of Respiratory and Critical Care Medicine, 170, 371-376. doi:10.1164/rccm.200307-9680C

[21] Royal Malaysia Police (2012) Statistical Report Road Accident 2011. Traffic Branch, Bukit Aman, Kuala Lumpur.

[22] Ahmad Noor Syukri, Z.A., Siti Atiqah, M.F., Fauziana, L. and Abdul Rahmat, A.M. (2012) MIROS crash investigation and reconstruction annual statistical report 20072011, MRR 05/2012 Malaysian Institute of Road Safety Research, Kuala Lumpur.

[23] Aishah (2004) Tesis Sarjana Kesihatan Masyarakat, Universiti Kebangsaan Malaysia, Kajian kelesuan serta faktor-faktor berkaitan dikalangan pemandu bas ekspres. Universiti Kebangsaan Malaysia, Bangi.

[24] Fadhli, Y., Norlen, M., Ilhamah, O., Rohayu, S. and Wong, S.V. (2008) Prevalence of fatigue among commercial bus drivers in Malaysia. Malaysian Institute of Road Safety Research, Kuala Lumpur.

[25] Mills, P.J., Kim, J.-H., Bardwell, W., Hong, S. and Dimsdale, J.E. (2008) Predictors of fatigue in obstructive sleep apnea. Sleep and Breathing November, 12, 397-399.

[26] Transport Statistics Malaysia, Ministry of Transport Ma- 
laysia 2011.

[27] Hartenbaum, N., Collop, N., Rosen, I.M., Philips, B., George, C.F.P., Rowley, J.A., Freedman, N., Weaver, T.E., Gurubhagavatula, I., Strohl, K., Leaman, H.M., Moffitt, G.L. and Rosekind, M.R. (2006) Sleep apnoea and commercial motor vehicle operators: Statement from the joint task force of the American college of chest physicians, the American college of occupational and environmental medicine, and the national sleep foundation. Journal Occupational Environmental Medicine, 48, S5-S37.
[28] Young, T., Blustein, J., Finn, L. and Palta, M. (1997) Sleep disordered breathing and motor vehicle accidents in a population-based sample of employed adults. Sleep, 20, 608-613.

[29] Norlen, M., Wahida, A.B., Ilhamah, O., Aimi, M.F., Mohamad, S.A. and Wong, S.V. (2012) Sleep apnea test among commercial vehicle drivers: The need versus the challenges for the implementation. Malaysian Institute of Road Safety Research, Kuala Lumpur. 